Дунаев Михаил Павлович,

д.т.н., профессор, Иркутский национальный исследовательский технический университет,

e-mail: mdunaev10@mail.ru

Дунаев Андрей Михайлович,

ассистент, Иркутский национальный исследовательский технический университет,

КЛАССИФИКАЦИЯ ПРИБЛИЖЕННЫХ МЕТОДОВ ПОСТРОЕНИЯ ПРОГРАММ ПРОВЕРОК

Dunaev M.P., Dunaev A.M.

\title{
CLASSIFICATION OF APPROXIMATE METHODS OF BUILDING VERIFICATION
} PROGRAMS

Аннотация. Рассмотрена классификация приближенных методов построения программ проверок, дополняющая общую классификацию.

Ключевые слова: классификация, метод, программа проверок.

Abstract. The classification of approximate methods of building verification programs, complementing the general classification, is considered.

Keywords: classification, method, verification program.

Авторами предложена классификация приближенных методов построения программ проверок, дополняющая общую классификацию, представленную в [1]. Такая классификация показана на рисунке 1.

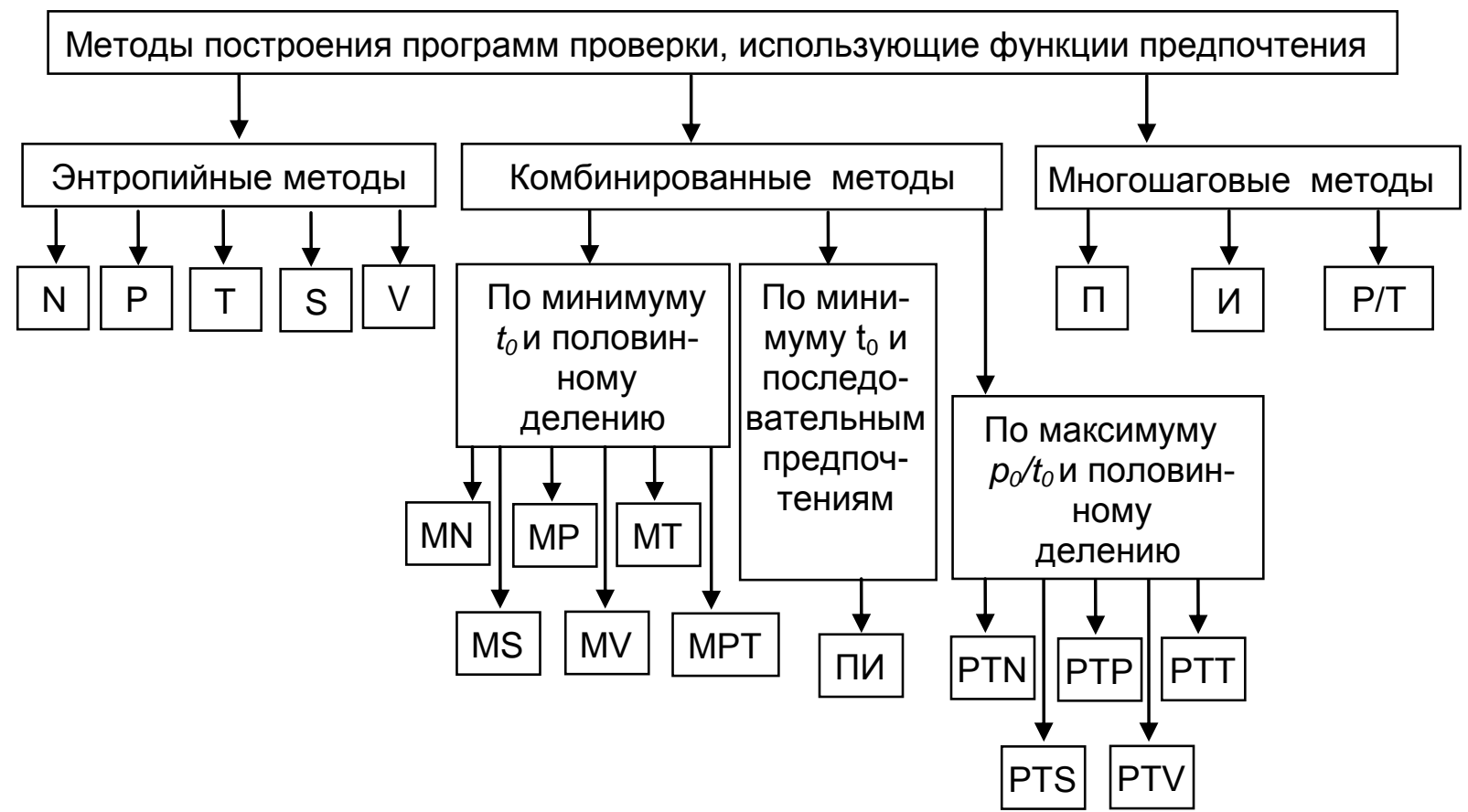

Рисунок 1 - Классификация приближенных методов построения программ проверок 
К группе многошаговых методов относятся следующие: П - алгоритм метода последовательных предпочтений [2]; И - алгоритм инженерного метода [2]; Р/Т - алгоритм времявероятностного метода [1].

К группе энтропийных методов относятся следующие: N - алгоритм метода половинного деления при равных весах технических состояний элементов $p\left(e_{i}\right)$ и временах их проверок $t\left(e_{i}\right)[1] ; \mathrm{P}$ - алгоритм метода половинного деления при неравных весах технических состояний элементов и равных временах их проверок [1]; Т - алгоритм метода половинного деления при равных весах технических состояний элементов и неравных временах их проверок [2]; S - алгоритм метода половинного деления с учётом характеристик доступности [2]; V алгоритм метода половинного деления с учётом относительной вероятности [2].

В группе комбинированных методов интерес представляет группа на основе методов с использованием критерия минимума времени первой проверки $t_{0}$ и различных модификаций метода половинного деления: MS - алгоритм метода поиска по критериям минимума времени первой проверки и с учётом характеристик относительной доступности [2]; MV - алгоритм метода поиска по критериям минимума времени первой проверки и с учётом характеристик относительной вероятности [2]; MN - алгоритм метода поиска по критериям минимума времени первой проверки и с учётом равных весов технических состояний элементов [2]; MP - алгоритм метода поиска по критериям минимума времени первой проверки, с учётом неравных весов технических состояний элементов и равного времени их проверок [2]; МТ - алгоритм метода поиска по критериям минимума времени первой проверки, с учётом равных весов технических состояний элементов и неравного времени их проверок [2]; МРТ - алгоритм метода поиска по критериям минимума времени первой проверки и с учётом времявероятностных характеристик технических состояний элементов $p\left(e_{i}\right) / t\left(e_{i}\right)[2]$.

\section{ЛИТЕРАТУРА}

1. Техническая диагностика: сборник трудов I всесоюзного совещания по технической диагностике / Под ред. П.П.Пархоменко. - М.: НАУКА, 1972. - 368 с.

2. Дунаев, М.П. Классификация логических алгоритмов методов технической диагностики / М.П. Дунаев, А.М. Дунаев // Повышение эффективности производства и использования энергии в условиях Сибири. - 2014. - № 1. - С. 5-8. 